HETEROCYCLES, Vol. 97, No. , 2018, pp. -. (C) 2018 The Japan Institute of Heterocyclic Chemistry Received, 5th October, 2017, Accepted, 14th November, 2017, Published online, DOI: $10.3987 / C O M-17-S(T) 1$

\title{
ASYMMETRIC TOTAL SYNTHESIS AND STRUCTURE CONFIRMATION OF (+)-(3E)-ISOLAUREFUCIN METHYL ETHER
}

\section{Te-ik Sohn, ${ }^{a}$ Byungsook Kim, ${ }^{a}$ Deukjoon Kim, ${ }^{\text {a* }}$ and Robert S. Paton ${ }^{\mathrm{b}}$}

\author{
${ }^{\mathrm{a} C}$ College of Pharmacy, Seoul National University, Seoul 08826, Korea \\ Fax: (+) 82-2-888-0649. E-mail: deukjoon@snu.ac.kr \\ ${ }^{\mathrm{b}}$ Chemical Research Laboratory, Department of Chemistry, University of Oxford, \\ Mansfield Road, Oxford OX1 3TA, United Kingdom
}

\begin{abstract}
An asymmetric total synthesis and structure confirmation of $(+)-3(E)$-isolaurefucin methyl ether (2a) was accomplished. Our synthesis features two complementary routes to construct the $\alpha, \alpha^{\prime}$-trans-2,8dioxabicyclo[5.2.1]decane skeleton of the natural product from $\alpha, \alpha^{\prime}$-trans- $\gamma, \delta$-unsaturated oxocene alcohol 7 , namely, an intramolecular epoxide opening route and a novel methoxyetherification route based on organoseleniummediated oxonium ion formation/fragmentation. A computational analysis was performed to model the observed different fragmentation behaviors of the respective oxonium ions $\mathbf{8}$ and $\mathbf{8}$ ' derived from $\alpha, \alpha^{\prime}$-trans- and $\alpha, \alpha^{\prime}$-cis- $\gamma, \delta$-unsaturated oxocene alcohols 7 and $\mathbf{7}$, during the organoselenium-mediated oxonium ion formation/fragmentation. Regarding the possibility of the natural product being an artifact, the reactivity of chlorofucin surrogate 16 and neoprelaurefucin surrogate 16' during methanolysis was compared, the results were in good agreement with calculations.
\end{abstract}

\section{INTRODUCTION}

Marine algae have been a prolific source of diverse halogenated secondary metabolites. ${ }^{1}$ Since Irie and co-workers first reported the isolation of (-)-(3E)-laurefucin (1) from the red alga Laurencia nipponica in 1972, new $\mathrm{C}_{15}$ acetogenins with a 2,8-dioxabicyclo[5.2.1]decane skeleton have been isolated. ${ }^{2}$ $(+)-(3 E)$-Isolaurefucin methyl ether (2a) was isolated along with $(+)-(3 E)$-chlorofucin $(\mathbf{2 b})$ by Bowden and co-workers from Dasyphyla plumariodes from Holmes Reef in the Coral Sea in 1993. ${ }^{3}$ The relative configuration of $(+)-(3 E)$-isolaurefucin methyl ether (2a) was established by extensive spectroscopic studies. The remarkable similarity of ${ }^{1} \mathrm{H}$ and ${ }^{13} \mathrm{C}$ NMR data of $(+)-(3 E)$-isolaurefucin methyl ether (2a) 
with those of $(+)-(3 E)$-chlorofucin $(\mathbf{2 b})^{4}$ and $(+)-(3 E)$-bromorofucin $(\mathbf{2 c})^{5}$ was instrumental in making the structural assignment. The absolute configuration of the marine natural product was tentatively assigned based on the co-occurrence with $(+)-(3 E)$-chlorofucin $(\mathbf{2 b})$ in this collection of D. plumariodes, the absolute configuration of which was previously determined by X-ray crystallography. ${ }^{4}$ It is of note that $(+)-(3 E)$-isolaurefucin methyl ether $(\mathbf{2 a}),(+)-(3 E)$-chlorofucin $(\mathbf{2 b})$, and $(+)-(3 E)$-bromorofucin (2c) all possess the $\alpha, \alpha^{\prime}$-trans-2,8-dioxabicyclo[5.2.1]decane skeleton in contrast to laurefucin (1) with an $\alpha, \alpha^{\prime}$-cis-2,8-dioxabicyclo[5.2.1]decane skeleton. A concern was raised by the isolation chemists that $(+)-(3 E)$-isolaurefucin methyl ether (2a) may be an artifact derived from methanolysis of the co-occurring $(+)-(3 E)$-chlorofucin $(\mathbf{2 b}) .^{3}$ The freeze-dried sample was reported to have been exhaustively extracted with dichloromethane and methanol. However, a careful reading of the original publication does not suggest that the isolation chemists considered a methanolysis process through an oxonium ion formation/fragmentation with net retention of configuration.

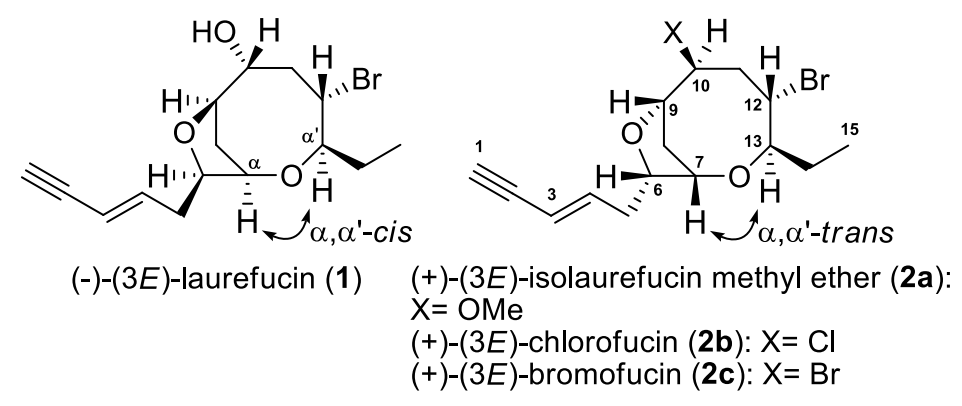

Figure 1. Representative Dioxabicyclic Marine Natural Products with the 2,8-Dioxabicyclo[5.2.1]decane Skeleton

We describe herein our asymmetric total synthesis of $(+)-3(E)$-isolaurefucin methyl ether (2a), which led to a confirmation of its proposed relative and absolute configuration. Our synthesis features two complementary routes to construct the $\alpha, \alpha^{\prime}$-trans-2,8-dioxabicyclo[5.2.1]decane skeleton of the natural product from $\alpha, \alpha^{\prime}$-trans- $\gamma, \delta$-unsaturated oxocene alcohol 7, namely, an intramolecular epoxide opening route and a novel methoxyetherification route based on an organoselenium-mediated oxonium ion formation/fragmentation route. A computational analysis was performed to model the observed different fragmentation behaviors of the respective oxonium ions $\mathbf{8}$ and $\mathbf{8}$ ' derived from $\alpha, \alpha^{\prime}$-trans- and $\alpha, \alpha^{\prime}$-cis- $\gamma, \delta$-unsaturated oxocene alcohols 7 and 7 ' during the organoselenium-mediated oxonium ion formation/fragmentation (vide infra). Regarding the possibility of the natural product being an artifact, the reactivity of chlorofucin surrogate $\mathbf{1 6}$ and neoprelaurefucin surrogate 16' during methanolysis was compared, and the results were in good agreement with these calculations. 


\section{RESULTS AND DISCUSSION}

The biosynthesis of $\mathrm{C}_{15}$ halogenated natural products from Laurencia species has been widely studied. ${ }^{6}$ Murai has demonstrated that a number of $\mathrm{C}_{15}$ halogenated natural products can be derived from laurediols, which are known to exist naturally as unequal mixtures of the $(3 E / Z, 12 E / Z, R R / S S)$ stereoisomers, ${ }^{7}$ via bromoperoxidase mediated bromonium ion induced cyclizations. For simplicity, in the above proposed biosynthetic pathway for dioxabicyclic marine natural products with a 2,8-dioxabicyclo[5.2.1]decane skeleton, only the (3E)-isomers are depicted (Scheme 1). Since this scheme has been discussed in detail in our very recently published asymmetric total syntheses of chlorofucins and bromofucins, ${ }^{8}$ that exegesis is not repeated in the present report. From this biosynthesis scheme, it seems clear that $(+)-(3 E)$-isolaurefucin methyl ether $(\mathbf{2 a}),(+)-(3 E)$-chlorofucin (2b), and (+)-(3E)-bromorofucin (2c) all share a common precursor, (3E, 12E, $S S)$-laurediol, while laurefucin (1) is derived from the opposite enantiomer.

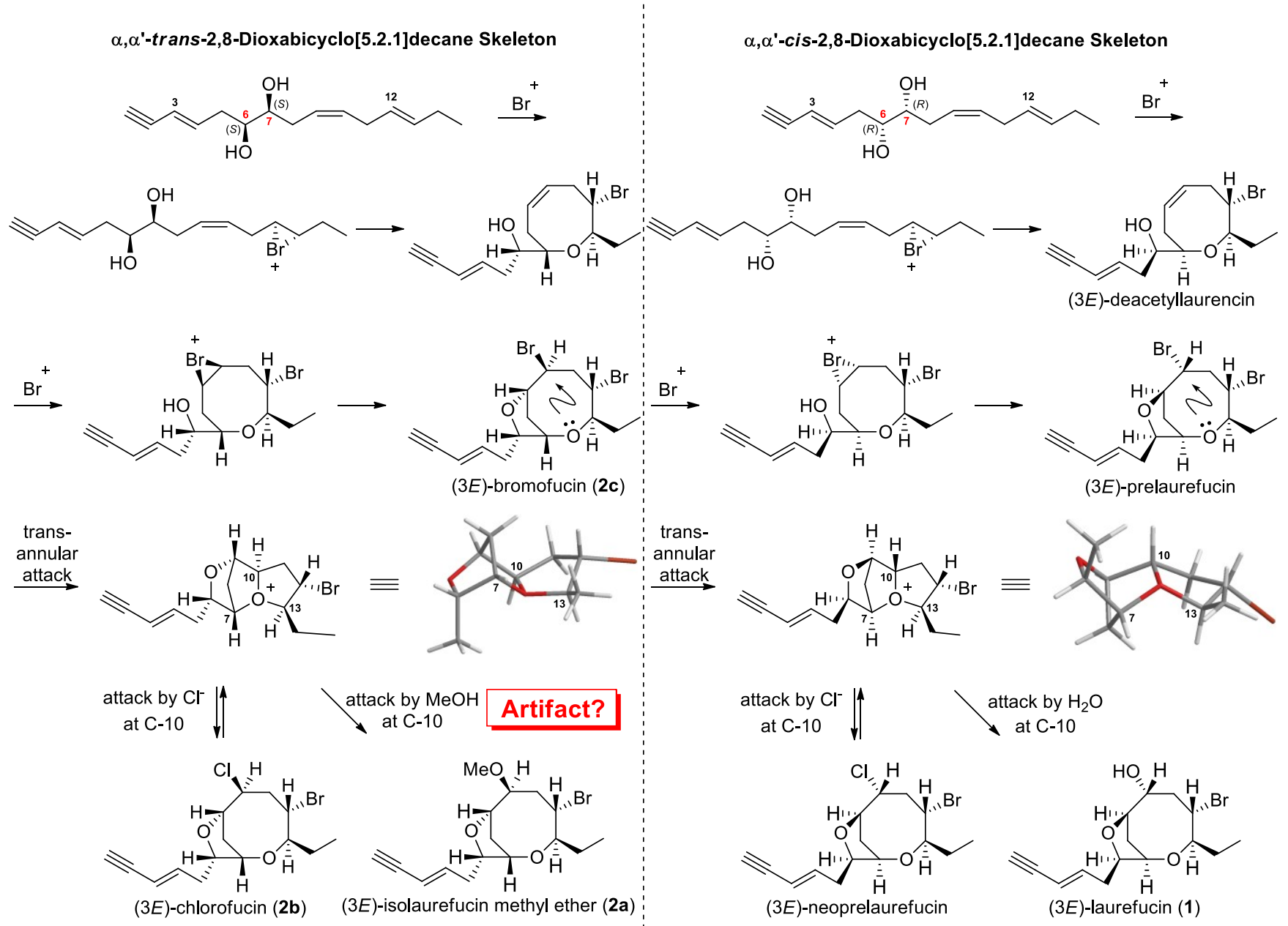

Scheme 1. Proposed Biosynthesis for Dioxabicyclic Marine Natural Products with 2,8-Dioxabicyclo[5.2.1]decane Skeleton 
As shown in our retrosynthetic plan (Scheme 2), we were confident that the $(3 E)$-enyne moiety of $(+)-(3 E)$-isolaurefucin methyl ether (2a) could be elaborated stereoselectively from terminal alkene 3 via our $(E)$-selective cross-metathesis/Colvin alkyne synthesis protocol. ${ }^{8,9}$ The terminal alkene $\mathbf{3}$ could in turn be prepared from isolaurefucin methyl ether surrogate 4 by application of the Grieco method. ${ }^{10}$

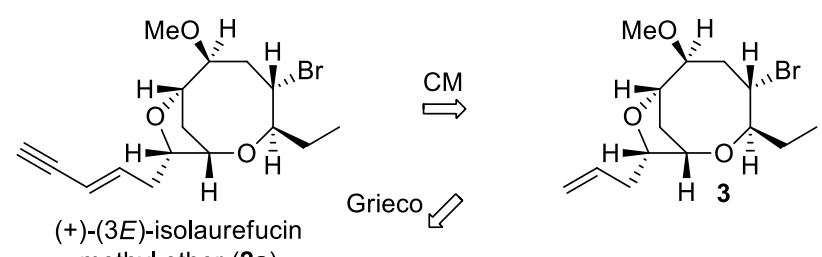

$(+)-(3 E)$-isolaurefucin

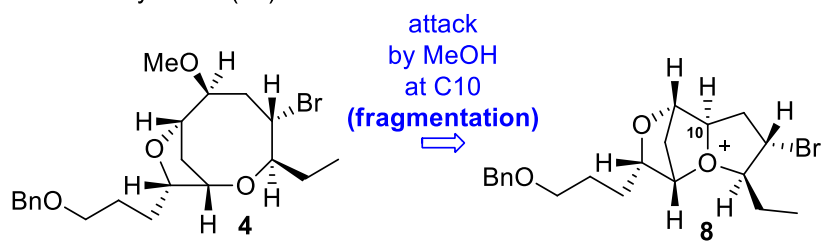

intermolecular
Williamson

transannular attack (oxonium ion formation)
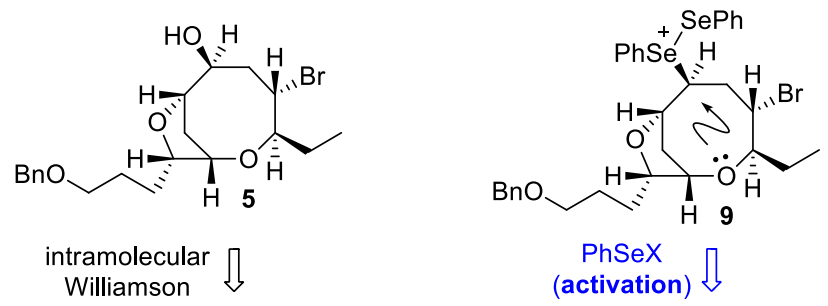

intramolecular
Williamson
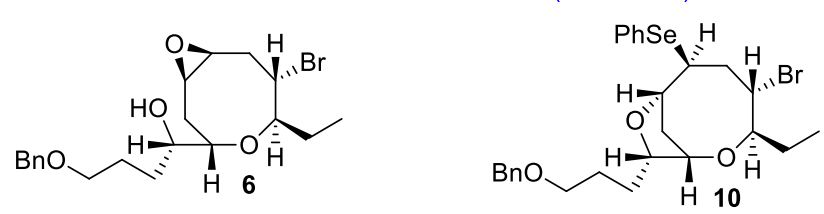

epoxidation \}
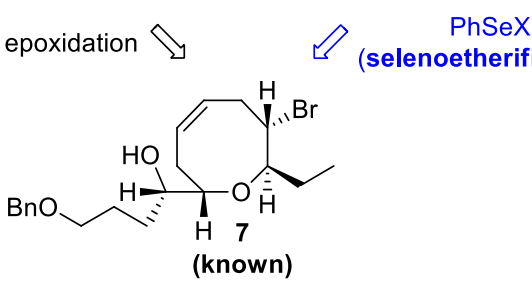

(selenoetherification)

Scheme 2. Retrosynthetic Plan for (+)-(3E)-Isolaurefucin Methyl Ether (2a)

We envisaged that the $\alpha, \alpha^{\prime}$-trans-2,8-dioxabicyclo[5.2.1]decane core in 4 could be constructed from the known $\alpha, \alpha^{\prime}$-trans- $\gamma, \delta$-unsaturated oxocene alcohol $7^{8,11}$ via two different routes. The first route involves an intramolecular Williamson ether synthesis from $\beta$-epoxy alcohol $\mathbf{6}$ and subsequent intermolecular Williamson methyl etherification of the resultant hydroxy-ether $\mathbf{5}$ to furnish the desired dioxabicyclic ether 4. However, the stereochemical outcome of epoxidation of $\alpha, \alpha$ '-trans- $\gamma, \delta$-unsaturated oxocene alcohol 7 caused some concern owing to the known conformational preferences ${ }^{12}$ of 
$\alpha, \alpha^{\prime}$-trans-oxocenes (vide infra). As a second approach, we were particularly intrigued by the possibility that a novel organoselenium-mediated alkoxyetherification of 7 in $\mathrm{MeOH}$, which involves a selenoetherification/activation/oxonium ion formation/fragmentation sequence $[\mathbf{7} \rightarrow \mathbf{1 0} \rightarrow \mathbf{9} \rightarrow \mathbf{8} \rightarrow \mathbf{4}]$ as depicted in the scheme, ${ }^{9}$ might provide a direct access to the dioxabicyclic core of isolaurefucin methyl ether 2. In the earlier mentioned recent synthesis of halofucins, we reported that key intermediate 7 could be synthesized from readily available $(R)-1$-penten-3-ol via an efficient nine-step sequence in $46 \%$ overall yield. ${ }^{8,11}$

Our computational analysis using DFT calculations with structural optimization of the two conformers (truncated model compounds) as depicted in Scheme 3, syn-conformer 7-syn, where the double bond and its ring oxygen atom have a syn-relationship with respect to the best plane through carbons C7, C8, $\mathrm{C} 11$, and $\mathrm{C} 12$, is predicted to be favored over the corresponding 7 -anti by $0.6 \mathrm{kcal} / \mathrm{mol}$ in the case of $\alpha, \alpha^{\prime}$-trans-oxocene alcohol 7. ${ }^{8}$ However, the above-referenced computational calculations suggested that epoxidation of $\alpha, \alpha^{\prime}$-trans-oxocene alcohol 7 would lead primarily to the undesired $\alpha$-epoxide 6' as the major isomer via electrophilic attack from the less sterically hindered $\alpha$-face of the molecule in its more stable syn-conformation 7-syn, as depicted in Scheme 3. In this context it is worth mentioning that osmylation of the related $\alpha, \alpha^{\prime}$-trans-oxocene 11 produced the corresponding $\alpha$-cis-diol as the major isomer in a 3:1 ratio. ${ }^{12 a}$ However, since the stereoselectivity of epoxidation of $\alpha, \alpha$-trans-oxocene alcohols such as 7 has not been reported ${ }^{13}$ to the best of our knowledge, and the conformers 7 -syn and 7 -anti are separated by only $0.6 \mathrm{kcal} / \mathrm{mol}$ according to the computational analysis, we proceeded to examine stereoselectivity of epoxidation of $\alpha, \alpha^{\prime}$-trans-oxocene alcohol 7 experimentally, despite the prediction.
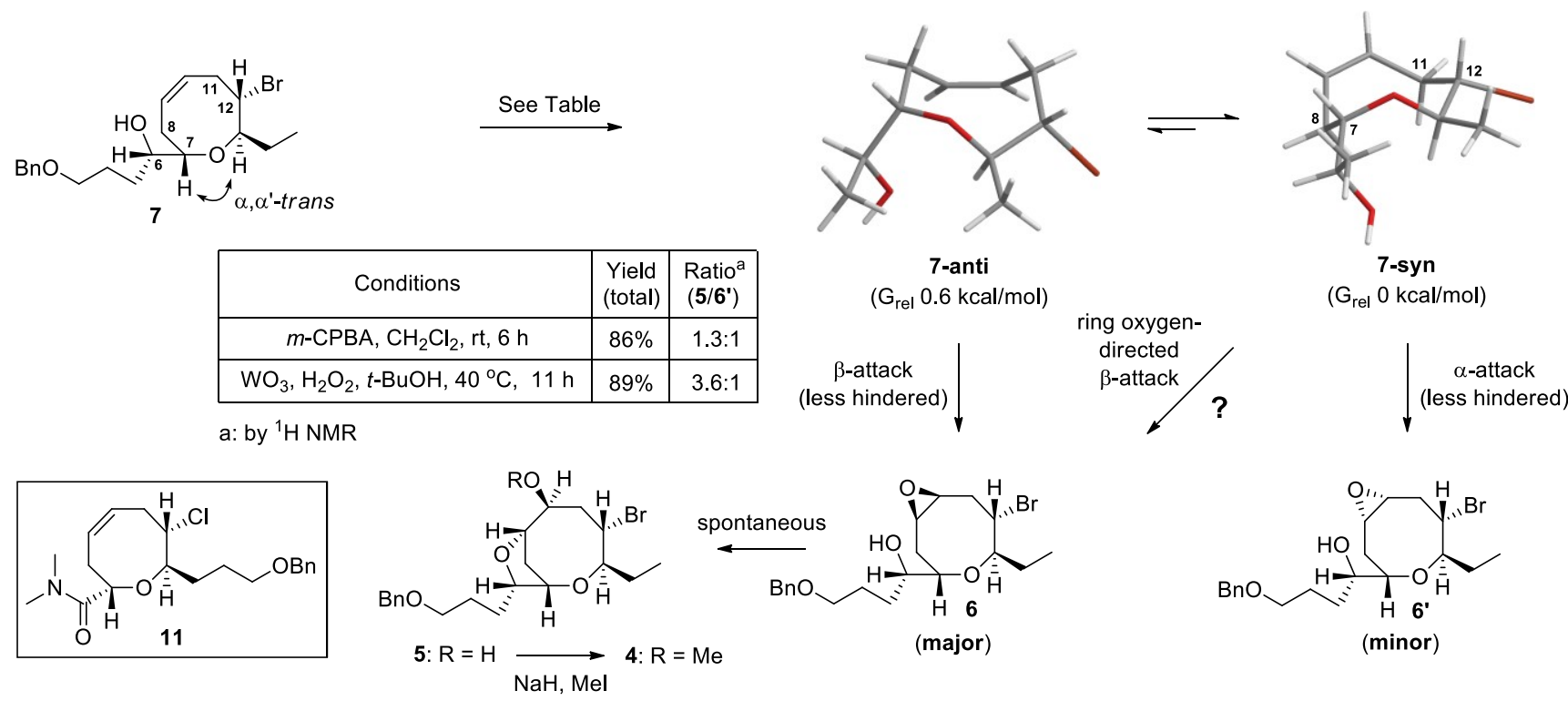

Scheme 3. Epoxidation and Intramolecular Epoxide Opening 
In the event, and contrary to our anticipation based on the above analysis, exposure of $\alpha, \alpha$-trans-oxocene alcohol 7 to $m$-CPBA at room temperature produced a 1.3:1 mixture of isolaurefucin surrogate 5 and $\alpha$-epoxide 6' in 86\% total yield. We presume that dioxabicyclic hydroxy-ether $\mathbf{5}$ arises from spontaneous cyclization of the desired $\beta$-epoxide $\mathbf{6}$ under the reaction conditions. The desired $\beta$-epoxide $\mathbf{6}$ would be produced by electrophilic attack from the less sterically hindered $\beta$-face of the less stable anti-conformer 7 -anti. ${ }^{14}$ It is worth mentioning that the desired $\beta$ epoxide 6 might also arise from the more stable syn-conformation 7-syn via interaction with its appropriately situated oxocene ring oxygen atom, which might be responsible for the reversal of the stereoselectivity anticipated on the basis of steric factors alone. ${ }^{16}$

In the course of our efforts to improve the stereoselectivity of the epoxidation, we have examined a variety of alternative epoxidation conditions. After extensive experimentation, we were pleased to find that treatment of $\gamma, \delta$-unsaturated alcohol 7 with tungsten oxide and hydrogen peroxide in $t$-butanol produced a 3.6:1 mixture (89\% total yield) of the desired isolaurefucin surrogate $\mathbf{5}$ and $\alpha$-epoxide $\mathbf{6}^{\prime} .{ }^{17}$ The hydroxyether 5 was transformed into the desired isolaurefucin methyl ether surrogate 4 by a Williamson methyl etherification without incident in quantitative yield [MeI, NaH, THF, $0{ }^{\circ} \mathrm{C}$ to $\mathrm{rt}, 3 \mathrm{~h}$, $100 \%]$.

Even though we were able to construct the isolaurefucin skeleton via the intramolecular epoxide opening route with decent stereoselectivity (3.6:1), we still wished to explore the direct synthesis of isolaurefucin methyl ether surrogate $\mathbf{4}$ via the projected novel organoselenium-mediated intramolecular alkoxyetherification of $\alpha, \alpha^{\prime}$-trans- $\gamma, \delta$-unsaturated oxocene alcohol 7 in $\mathrm{MeOH}$. In our synthesis of laurefucin (1), ${ }^{9}$ we reported that exposure of $\alpha, \alpha^{\prime}-c i s-\gamma, \delta$-unsaturated oxocene alcohol 7 ' to excess $N$-phenylselenophthalimide (N-PSP) ${ }^{18}$ in the presence of PTSA in $\mathrm{MeCN} / \mathrm{H}_{2} \mathrm{O}$ at room temperature for $2.5 \mathrm{~h}$ produced laurefucin surrogate hydroxy-ether $\mathbf{5}$ ' in quantitative yield. This efficient process has been rationalized as due to phenylselenoetherification of oxocene alcohol 7 ' and subsequent activation of the phenylselenyl group ${ }^{19}$ in selenoether 10' by N-PSP, followed by transannular participation by the ring oxygen in the resultant adduct 9', which would generate key oxonium ion 8' as depicted in Scheme 4. Ensuing nucleophilic attack by the water at C10 in oxonium ion $\mathbf{8}$ ' would then lead to hydroxyether 5', with an overall double inversion. As a corollary, subjection of the same substrate 7 ' to otherwise comparable conditions, except with $\mathrm{MeOH}$ as the solvent instead of $\mathrm{H}_{2} \mathrm{O}$, effected the desired alkoxyetherification to produce methoxy-ether 4' directly as the exclusive product in very good yield, as summarized on the right side of the scheme and shown in the table. A structure confirmation for methoxy ether 4' was possible by correlation with the product from Williamson methyl etherification of the known hydroxyl-ether 5, 9 
isolaurefucin series $\underline{\left(\alpha, \alpha^{\prime}-\text { trans) }\right.}$

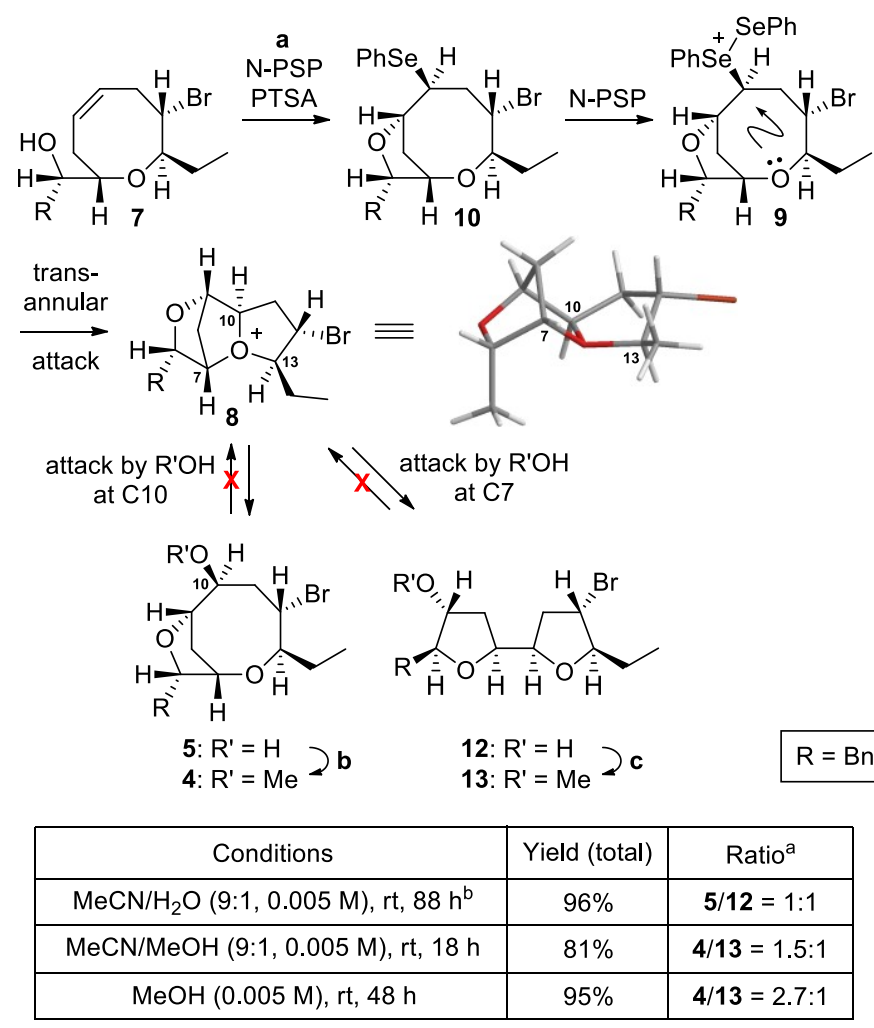

a: by ${ }^{1} \mathrm{H}$ NMR; b: additional N-PSP \& PTSA were added after $40 \mathrm{~h}$
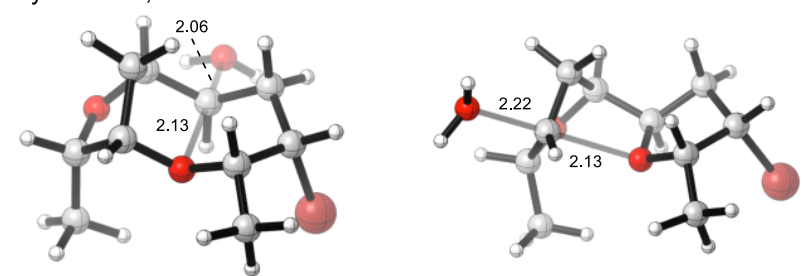

attack by $\mathrm{H}_{2} \mathrm{O}$ at $\mathrm{C} 10: \mathrm{G}_{\text {act }}=19.7$

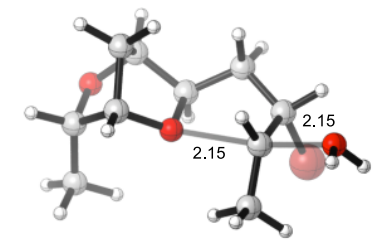

attack by $\mathrm{H}_{2} \mathrm{O}$ at $\mathrm{C} 13: \mathrm{G}_{\text {act }}=20.7$ laurefucin series $\left(\alpha, \alpha^{\prime}-\right.$ cis $)$
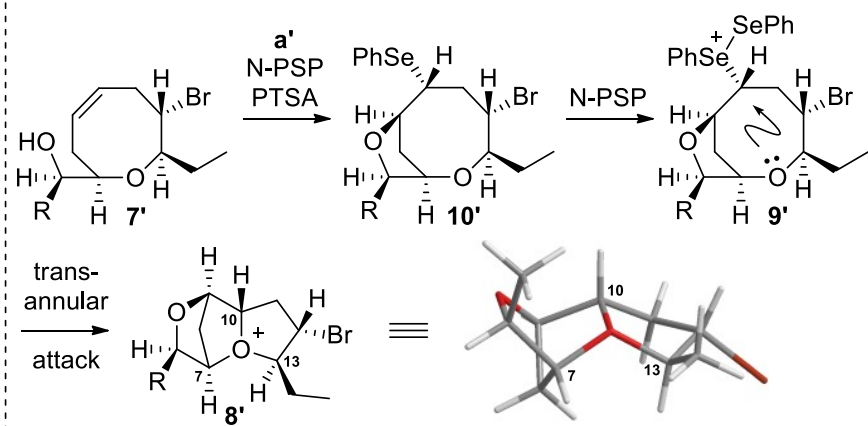

attack by $\mathrm{R}^{\prime} \mathrm{OH}$
at $\mathrm{C} 10$

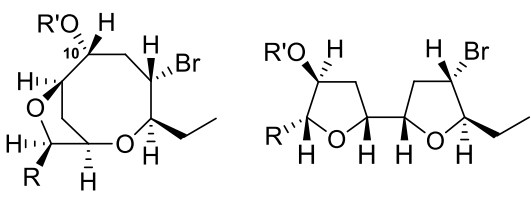

$5^{\prime}: R^{\prime}=H$
$4^{\prime}: R^{\prime}=M e$$\quad \begin{aligned} & 12^{\prime}: R^{\prime}=H \\ & 13^{\prime}: R^{\prime}=M e\end{aligned}$

\begin{tabular}{|c|c|c|}
\hline Conditions & Yield (total) & Ratio $^{\text {a }}$ \\
\hline $\mathrm{MeCN} / \mathrm{H}_{2} \mathrm{O}(9: 1,0.005 \mathrm{M}), \mathrm{rt}, 2.5 \mathrm{~h}$ & $100 \%$ & $\mathbf{5}^{\prime}$ only \\
\hline $\mathrm{MeCN} / \mathrm{MeOH}(9: 1,0.005 \mathrm{M}), \mathrm{rt}, 1 \mathrm{~h}$ & $93 \%$ & $\mathbf{4}^{\prime}$ only \\
\hline $\mathrm{MeOH}(0.005 \mathrm{M}), \mathrm{rt}, 45 \mathrm{~min}$ & $93 \%$ & $\mathbf{4}^{\prime}$ only \\
\hline
\end{tabular}

a: by ${ }^{1} \mathrm{H}$ NMR
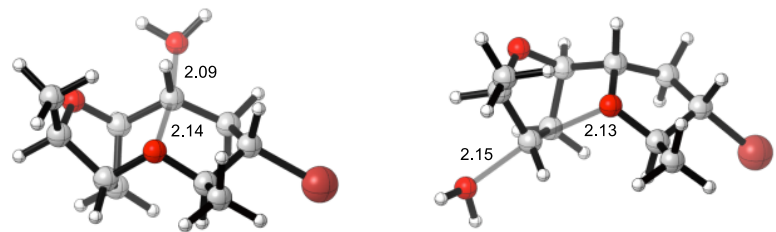

attack by $\mathrm{H}_{2} \mathrm{O}$ at $\mathrm{C} 10: \mathrm{G}_{\text {act }}=18.3$ attack by $\mathrm{H}_{2} \mathrm{O}$ at $\mathrm{C} 7: \mathrm{G}_{\text {act }}=19.7$

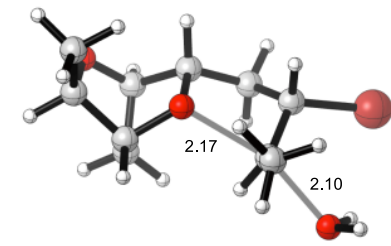

attack by $\mathrm{H}_{2} \mathrm{O}$ at $\mathrm{C} 13: \mathrm{G}_{\text {act }}=30.2$

Scheme 4. One-Pot Organoselenium-Mediated Oxonium Ion Formation/Fragmentation; b') MeI, NaH, THF, rt, 2 h, 97\%; b) MeI, NaH, THF, $0{ }^{\circ} \mathrm{C}$ to rt, 3 h, 100\%; c) MeI, NaH, THF/DMF (1:1), rt, 2 h, $97 \%$.

In an experiment parallel to that of $\alpha, \alpha^{\prime}-c i s-\gamma, \delta$-unsaturated oxocene alcohol 7', subjection of $\alpha, \alpha$-trans- $\gamma, \delta$-unsaturated alcohol 7 to the abovementioned comparable hydroxyetherification conditions gave rise to a 1:1 mixture ( $96 \%$ total yield) of the desired hydroxyl-ether 5 with an $\alpha, \alpha$-trans-2,8-dioxabicyclo[5.2.1]decane skeleton and bis-tetrahydrofuranyl alcohol 12. This latter presumably arises from attack at the $\mathrm{C} 7$ position of oxonium ion $\mathbf{8}$, and we were somewhat surprised 
that it was produced in such abundance. Similarly, $\alpha, \alpha^{\prime}-\operatorname{trans}-\gamma, \delta$-unsaturated alcohol 7 gave rise to a 1.5:1 mixture of the desired methoxy-ether $\mathbf{4}$ and bis-tetrahydrofuranyl methyl-ether $\mathbf{1 3}$ (81\% total yield) upon exposure to conditions that were comparable except with $\mathrm{MeCN} / \mathrm{MeOH}(9: 1)$ as the solvent instead of $\mathrm{MeCN} / \mathrm{H}_{2} \mathrm{O}$ (9:1). Somewhat fortunately, $\alpha, \alpha^{\prime}$-trans- $\gamma, \delta$-unsaturated alcohol 7 furnished a 2.7:1 mixture (95\% total yield) of the desired methoxy-ether $\mathbf{4}$ and bis-THF methyl ether $\mathbf{1 3}$ in $\mathrm{MeOH}$ alone, as summarized in the tables. We are still formulating an explanation for the subtle effect of solvent on the fragmentation pattern of the oxonium ion observed here.

The structure of bis-tetrahydrofuranyl alcohol 12 was determined by conversion to the corresponding bromide, the enantiomer of which was known from our synthesis of elatenyne, ${ }^{11}$ by a three-step sequence: 1) Mitsunobu inversion, 2) saponification, and 3) bromination with inversion of configuration. In addition, the structure of bis-tetrahydrofuranyl methyl ether $\mathbf{1 3}$ was firmly established by Williamson methyl etherification of $\mathbf{1 2}$. Formation of methoxy-ether $\mathbf{4}$ or bis-tetrahydrofuranyl methyl ether $\mathbf{1 3}$ by respective attack of $\mathrm{MeOH}$ at $\mathrm{C} 10$ or $\mathrm{C} 7$ of oxonium ion $\mathbf{8}$ seems to be an irreversible process under the reaction conditions, since resubjection of $\mathbf{4}$ or $\mathbf{1 3}$ to the reaction conditions [PTSA (0.2 eq), MeOH $(0.005 \mathrm{M}), \mathrm{rt}, 48 \mathrm{~h}]$ does not produce any cross-over product. It is of note that $\alpha, \alpha^{\prime}-c i s-\gamma, \delta$-unsaturated oxocene alcohol 7' reacts faster than the corresponding $\alpha, \alpha^{\prime}$-trans- $\gamma, \delta$-unsaturated oxocene alcohol 7, since compared to the corresponding $\alpha, \alpha^{\prime}$-cis-prelaurefucin surrogate 9', $\alpha, \alpha^{\prime}$-trans-disubstituted intermediate 9 (related to bromofucin) is less favorably disposed toward transannular cyclization via intramolecular attack by the oxocane oxygen atom to form dioxatricyclic oxonium ion $\mathbf{8}$ (vide infra).

To gain some insight on the observed different fragmentation behaviors of the respective oxonium ions 8 and 8', we embarked on computational studies as summarized in Scheme 4. The results of simulating transition state structures for the interception of $\alpha, \alpha^{\prime}$-cis-oxonium ion $\mathbf{8}^{\prime}$ by water indicated that attack at $\mathrm{C} 10$ is kinetically preferred over C7 by an estimated $1.4 \mathrm{kcal} / \mathrm{mol}$, and over C13 by an estimated 11.9 $\mathrm{kcal} / \mathrm{mol}$, which agrees with the experimental findings (5' from $\mathrm{C} 10$ attack as sole product). On the other hand, simulation of the transition state structures for interception of $\alpha, \alpha^{\prime}$-trans-oxonium ion 8 by water suggests that $\mathrm{C} 7$ attack (to give 12) in this case would be the kinetically preferred pathway over attack at $\mathrm{C} 10$ (to give 5) and $\mathrm{C} 13$. The results from calculations do not parallel those from experiment very well $(\mathbf{5} / \mathbf{1 2}=1: 1)$, although the bis-tetrahydofuranyl product resulting from $\mathrm{C} 7$ attack predominates relative to that from the $\alpha, \alpha^{\prime}$-cis-oxonium ion. 

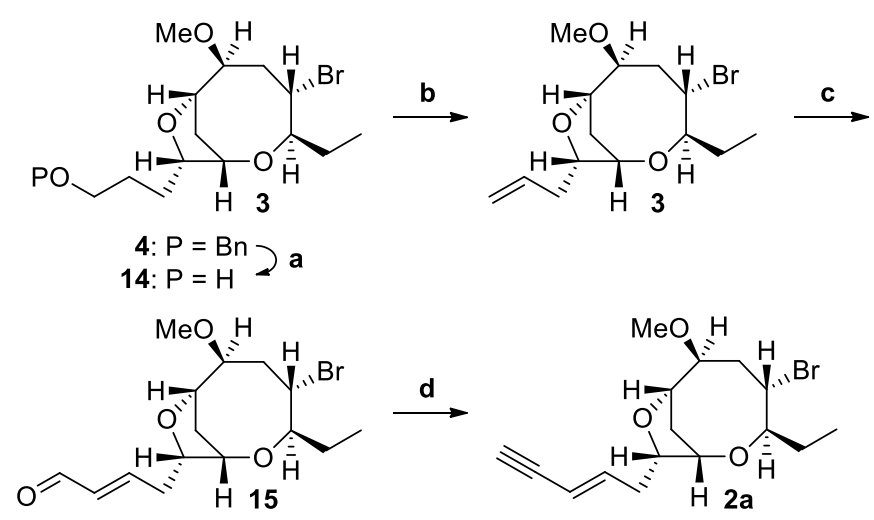

Scheme 5. Completion of the Synthesis. a) $\mathrm{Pd}(\mathrm{OH})_{2} / \mathrm{C}, \mathrm{H}_{2}$, THF, rt, $30 \mathrm{~min}, 98 \%$; b) $o-\mathrm{NO}_{2}-\mathrm{PhSeCN}_{\text {, }}$ $\mathrm{Oct}_{3} \mathrm{P}$, THF, rt, $30 \mathrm{~min}$, then $\mathrm{H}_{2} \mathrm{O}_{2}$, rt, $21 \mathrm{~h}, 92 \%$; c) crotonaldehyde, [( $\left.\mathrm{H}_{2} \mathrm{IMes}\right)\left(\mathrm{PCy}_{3}\right)\left(\mathrm{Cl}_{2}\right) \mathrm{Ru}=\mathrm{CHPh}$, $\mathrm{CH}_{2} \mathrm{Cl}_{2}, 40{ }^{\circ} \mathrm{C}, 1 \mathrm{~h}$, then DMSO, rt, $12 \mathrm{~h}$; d) TMSCHN 2 , LDA, THF, -78 to $0{ }^{\circ} \mathrm{C}, 1.5 \mathrm{~h}, 70 \%$ (2 steps).

To complete the synthesis, we turned our attention to elaboration of the $(3 E)$-enyne moiety of $(+)-(3 E)$-isolaurefucin methyl ether via our $(E)$-selective cross-metathesis/Colvin alkyne synthesis protocol. ${ }^{9}$ To the end, hydrogenolysis of benzyl protecting group of $\mathbf{4}$, followed by the conversion of terminal hydroxyl in the resultant alcohol 14 into terminal olefin in 3 by Grieco's method, ${ }^{10}$ set up the system for stereoselective introduction of the $(E)$-enyne unit $(87 \%, 2$ steps). Cross-metathesis of terminal alkene 3 with crotonaldehyde using the Grubbs second generation catalyst, ${ }^{20}$ followed by exposure of the resulting trans- $\alpha, \beta$-unsaturated aldehyde 15 to lithio TMS-diazomethane, ${ }^{21}$ delivered $(+)-(3 E)$-isolaurefucin methyl ether (2a) in $74 \%$ yield for the two steps. The spectral and optical rotation data for our synthetic material were in good agreement with those of the natural product: $[\alpha]^{25}+9.5(c$ $\left.1.04, \mathrm{CHCl}_{3}\right)\left[\right.$ lit. $\left.^{3}[\alpha]_{\mathrm{D}}+8.0\left(c 0.3, \mathrm{CHCl}_{3}\right)\right]$.

Having accomplished an asymmetric total synthesis of $(+)-(3 E)$-isolaurefucin methyl ether (2a), we proceeded to address the possibility of its being an artifact derived from co-occurring $(+)-(3 E)$-chlorofucin (2b) during an extraction procedure in methanol such as in the isolation report. To this end, our $\alpha, \alpha^{\prime}$-trans-chlorofucin surrogate $\mathbf{1 6}^{8,11}$ and $\alpha, \alpha^{\prime}$-cis-neoprelaurefucin surrogate 16 ${ }^{9}{ }^{9}$ were subjected to the simulated extraction conditions, i.e. in methanol solution. We also evaluated this reaction scenario computationally, and DFT calculations indicated that oxonium formation by nucleophilic displacement of chloride occurs with an estimated barrier of $22.9 \mathrm{kcal} / \mathrm{mol}$ for $\alpha, \alpha^{\prime}$-cis-neoprelaurefucin surrogate 16', and that is possible in its most stable conformation as depicted in the right side of Scheme 6. On the other hand, the ring ether oxygen in $\alpha, \alpha^{\prime}$-trans-chlorofucin surrogate $\mathbf{1 6}$ is only able to attack after the ring has flipped from the more stable conformation to a less stable conformation with the $\mathrm{Me}$ and $\mathrm{Br}$ groups in a trans-diaxial orientation as shown in the left side of the scheme. This is necessary so that the resulting 5,5-bicyclic formed will be cis- rather than 
trans-fused. It is perhaps surprising that the ring-flipped form of the trans halo ether lies uphill only by an estimated $1.7 \mathrm{kcal} / \mathrm{mol}$ - however the activation barrier of this conformational change has not been evaluated computationally, and could be significant. The nucleophilic attack of chloride by the ring ether oxygen proceeds with a barrier estimated to be $23.8 \mathrm{kcal} / \mathrm{mol}$, which would lead to a slower reaction by a factor of approximately 5 to give $\alpha, \alpha^{\prime}$-trans-dioxatricyclic oxonium ion 8 at $298{ }^{\circ} \mathrm{K}$.

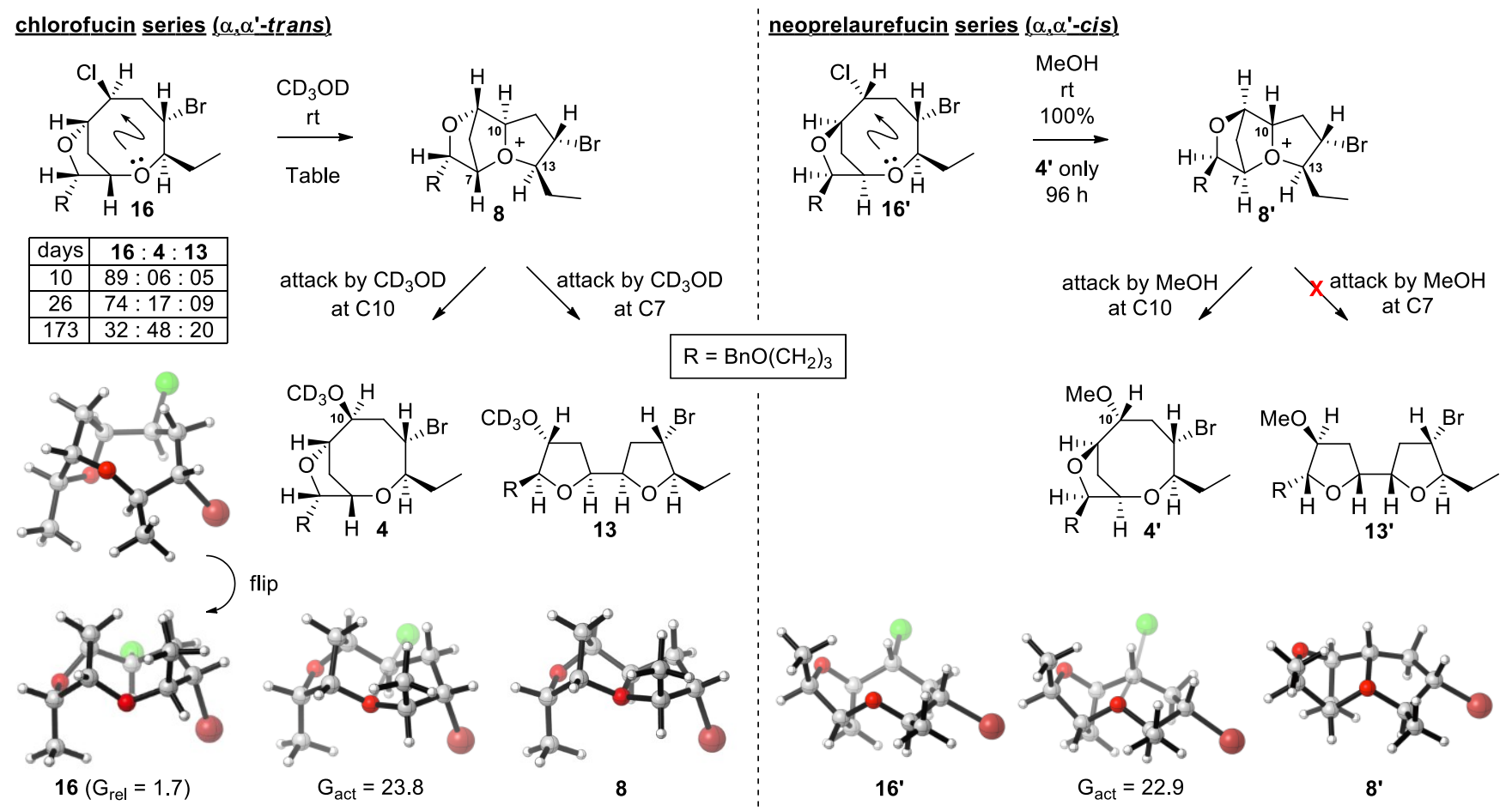

Scheme 6. Reactivity of Chlorofucin Surrogate 16 and Neoprelaurefucin Surrogate 16' and the Artifact Issue

Methanolysis of $\alpha, \alpha^{\prime}$-cis-neoprelaurefucin surrogate 16' was complete after $96 \mathrm{~h}$ at room temperature in methanol $(0.005 \mathrm{M})$ to produce laurefucin methyl ether surrogate 4' exclusively in quantitative yield, as predicted by calculation. ${ }^{22}$ On the other hand, methanolysis of $\alpha, \alpha^{\prime}$-trans-chlorofucin surrogate 16 was much more sluggish, with only approximately $25 \%$ conversion of $\mathbf{1 6}$ to the corresponding methyl ether 4 after 1 month's time by ${ }^{1} \mathrm{H}$ NMR analysis in $\mathrm{CD}_{3} \mathrm{OD}$, and $75 \%$ conversion after 6 months. ${ }^{23}$ More significantly, bis(2,2')-furanyl methyl ether 13 (4/13 = 2:1 by NMR) was produced as a minor isomer. This is in line with our earlier mentioned observation that in the case of $\alpha, \alpha^{\prime}$-trans-dioxatricyclic oxonium ion $\mathbf{8}$, greater amounts of bis(2,2')-furan are formed by the $\mathrm{C} 7$ attack in a kinetically controlled process relative to the $\alpha, \alpha^{\prime}$-cis-oxonium ion 8'. Furthermore, upon refluxing our previously synthesized sample ( $\sim 3 \mathrm{mgs})$ of $(+)-(3 E)$-chlorofucin (2b) in methanol for 5 days, $(+)-(3 E)$-isolaurefucin methyl ether (2a) was cleanly produced along with a bis-tetrahydrofuran derivative (45\% conversion; $4.6: 1$ ratio in 
favor of 2a by ${ }^{1} \mathrm{H}$ NMR analysis). The isolation chemists reported that the freeze-dried sample was exhaustively extracted with dichloromethane and methanol. Out of the resultant crude extract (1.12 g, $0.5 \%)$ from the freeze-dried tissue $(232 \mathrm{~g}),(+)-(3 E)$-chlorofucin $(\mathbf{2} \mathbf{b} ; 8.9 \mathrm{mg})$ and $(+)-(3 E)$-isolaurefucin methyl ether (2a; $5.9 \mathrm{mg})$ were isolated after chromatographic purification (column chromatography followed by HPLC) using mixtures of light petroleum and ethyl acetate as eluent. Significantly, no mention was made of any exposure of the sample to methanol after the initial extraction. Although we do not know the details of the "exhaustive extraction with dichloromethane and methanol", and we have demonstrated that $(+)-(3 E)$-chlorofucin $(\mathbf{2 b})$ can be converted to $(+)-(3 E)$-isolaurefucin methyl ether $(\mathbf{2 a})$ in methanol, the above-described low reactivity of $\alpha, \alpha^{\prime}$-trans-chlorofucin surrogate $\mathbf{1 6}$ and synthetic $(+)-(3 E)$-chlorofucin (2b) toward methanol suggests that $(+)-(3 E)$-isolaurefucin methyl ether $(\mathbf{2 a})$ is not an artifact derived from methanolysis of the co-occurring $(+)-(3 E)$-chlorofucin $(\mathbf{2 b})$. A future experiment to reisolate the material without using methanol as solvent would clarify the artifact issue.

\section{CONCLUSIONS}

In summary, an asymmetric total synthesis and structure confirmation of $(+)-3(E)$-isolaurefucin methyl ether (2a) has been accomplished. Our synthesis features two complementary routes, namely an intramolecular epoxide opening route and an organoselenium-mediated oxonium ion formation/fragmentation route, to construct the $\alpha, \alpha^{\prime}$-trans-2,8-dioxabicyclo[5.2.1]decane skeleton of the natural product from $\alpha, \alpha^{\prime}$-trans- $\gamma, \delta$-unsaturated oxocene alcohol 7. More importantly, the rationale for the observed different fragmentation behaviors of the respective oxonium ions $\mathbf{8}$ and $\mathbf{8}$ ' derived from $\alpha, \alpha^{\prime}$-trans- and $\alpha, \alpha^{\prime}-c i s-\gamma, \delta$-unsaturated oxocene alcohols 7 and 7 ' during the organoselenium-mediated oxonium ion formation/fragmentation were provided.

\section{EXPERIMENTAL}

Supporting Information. Experimental procedures; spectroscopic and analytical data for all new compounds including copies of NMR spectra.

\section{ACKNOWLEDGEMENTS}

We thank Professor B. F. Bowden (James Cook Univ. of North Queensland) for helpful discussions. This work was supported by the NRF grant funded by the MEST, Korea (No. 20120000847), the Oxford University Press John Fell fund, and the Royal Society (RG110617).

\section{REFERENCES AND NOTES}

1. a) D. J. Faulkner, Nat. Prod. Rep., 2002, 19, 1; b) K. L. Erickson, in Marine Natural Products, Vol. 5, 
(ed. by P. J. Scheuer), Academic Press, New York, 1983; Vol. 5, pp. 131-257.

2. a) A. Fukuzawa, E. Kurosawa, and T. Irie, Tetrahedron Lett., 1972, 13, 3; b) A. Furusaki, E. Kurosawa, A. Fukuzawa, and T. Irie, Tetrahedron Lett., 1973, 14, 4579; c) S. J. Wratten and D. J. Faulkner, J. Org. Chem., 1977, 42, 3343; d) G. M. Koenig and A. D. Wright, J. Nat. Prod., 1994, 57, 477.

3. R. de Nys, J. C. Coll, A. R. Carroll, and B. F. Bowden, Aust. J. Chem., 1993, 46, 1073.

4. B. M. Howard, G. R. Schulte, W. Fenical, B. Solheim, and J. Clardy, Tetrahedron, 1980, 36, 1747.

5. J. C. Coll and A. D. Wright, Aust. J. Chem., 1989, 42, 1685.

6. a) A. Murai, in Comprehensive Natural Products Chemistry, Vol. (ed. by D. H. R. Barton, O. Meth-Cohn, and K. Nakinishi), Elsevier, Oxford, 1999, p 303; b) H. Kikuchi, T. Suzuki, E. Kurosawa, and M. Suzuki, Bull. Chem. Soc. Jpn., 1991, 64, 1763.

7. A. Fukuzawa, T. Honma, Y. Takasugi, and A. Murai, Phytochemistry, 1993, 32, 1435.

8. a) B. Kim, Ph. D. Thesis, Seoul National University, 2011; b) B. Kim, T. Sohn, D. Kim, and R. S. Paton, Chem. Eur. J., 2017, submitted.

9. B. Kim, M. Lee, M. J. Kim, H. Lee, S. Kim, D. Kim, M. Koh, S. B. Park, and K. J. Shin, J. Am. Chem. Soc., 2008, 130, 16807.

10. P. A. Grieco, S. Gilman, and M. Nishizawa, J. Org. Chem., 1976, 41, 1485.

11. Synthesis of the antipode of $\mathbf{7}$ was recently disclosed in detail in connection with our synthetic work on elatenyne: B. S. Dyson, J. W. Burton, T. Sohn, B. Kim, H. Bae, and D. Kim, J. Am. Chem. Soc., $2012,134,11781$.

12. a) H. Kim, H. Lee, D. Lee, S. Kim, and D. Kim, J. Am. Chem. Soc., 2007, 129, 2269; For the crystal structures of $\alpha, \alpha^{\prime}$-trans-oxocene natural products, see: b) R. B. Kinnel, R. K. Dieter, J. Meinwald, D. Van Engen, J. Clardy, T. Eisner, M. O. Stallard, and W. Fenical, Proc. Natl. Acad. Sci. U.S.A., 1979, 76, 3576; c) E. Manzo, M. L. Ciavatta, M. Gavagnin, R. Puliti, E. Mollo, Y.-W. Guo, C. A. Mattia, L. Mazzarella, and G. Cimino, Tetrahedron, 2005, 61, 7456.

13. In the case of diastereomeric $\alpha, \alpha^{\prime}$-cis-oxocene alcohol 7', the corresponding $\beta$-epoxide was produced as the exclusive isomer via electrophilic attack from the less sterically hindered $\beta$-face of the molecule in its more stable anti-conformation, which is computed to be more stable than the corresponding syn-conformation by $1.6 \mathrm{kcal} / \mathrm{mol}$, see ref. 8,9 .

14. It is worth mentioning that the undesired $\alpha$-epoxide $6^{\prime}$ ' might also arise from anti-conformation 7-anti via a Henbest-type hydrogen-bonding interaction with $\mathrm{C}(6)$-bis-homoallylic hydroxyl group. ${ }^{15}$ However, this possibility could be safely ruled out by the observations that the TBS ether or acetate of 7 produced a roughly 1:1 mixture of the corresponding $\alpha$-and $\beta$-epoxides under comparable conditions; see the Supporting Information. 
15. a) H. B. Henbest and R. A. L. Wilson, J. Chem. Soc., 1959, 1958; b) A. M. Hoveyda, D. A. Evans, and G. C. Fu, Chem. Rev., 1993, 93, 1307.

16. For an early example of ether-directed epoxidation, see: C. H. Heathcock, C. M. Tice, and T. C. Germroth, J. Am. Chem. Soc., 1982, 104, 6081.

17. a) H. C. Stevens and A. J. Kaman, J. Am. Chem. Soc., 1965, 87, 734; b) B. S. Lane and K. Burgess, Chem. Rev., 2003, 103, 2457; c) D. H. Koo, M. Kim, and S. Chang, Org. Lett., 2005, 7, 5015.

18. K. C. Nicolaou, D. A. Claremon, W. E. Barnette, and S. P. Seitz, J. Am. Chem. Soc., 1979, 101, 3704.

19. A. M. Morella and A. D. Ward, Tetrahedron Lett., 1984, 25, 1197.

20. For examples of olefin cross-metathesis with crotonaldehyde, see: a) J. P. Morgan, C. Morrill, and R. H. Grubbs, Org. Lett., 2002, 4, 67; b) B. M. Trost, J. L. Gunzner, O. Dirat, and Y. H. Rhee, J. Am. Chem. Soc., 2002, 124, 10396; c) ref. 9.

21. a) E. W. Colvin and B. J. Hamill, J. Chem. Soc., Chem. Commun., 1973, 151; b) S. Ohira, K. Okai, and T. Moritani, J. Chem. Soc., Chem. Commun., 1992, 721; c) K. Miwa, T. Aoyama, and T. Shioiri, Synlett, 1994, 107.

22. $O$-Methyllaurefucin (i.e., laurefucin methyl ether) has been isolated from the methanol extracts of Laurencia nipponica, which must be an artifact derived from solvolysis of the putative prelaurefucin or neoprelaurefucin during the extraction procedures. ${ }^{6 \mathrm{~b}}$

23. Although the observed ratio (4/13) was close to unity at 10 day's time, the absolute values are quite small and this result could be due to inaccuracies in the NMR integration under those conditions; see the Supporting Information. 